\title{
Pyrolysis product distribution of waste newspaper in MSW
}

\author{
Chao-Hsiung $\mathrm{Wu}^{\mathrm{a}, *}$, Ching-Yuan Chang ${ }^{\mathrm{b}}$, \\ Chao-Heng Tseng ${ }^{\mathrm{c}}$, Jyh-Ping Lin ${ }^{\mathrm{d}}$ \\ a Department of Environmental Engineering, Da-Yeh University, Chang-Hwa 515, Taiwan \\ ${ }^{\mathrm{b}}$ Graduate Institute of Environmental Engineering, National Taiwan University, Taipei 106, Taiwan \\ ${ }^{\mathrm{c}}$ Department of Civil Engineering, National Taipei University of Technology, Taipei 106, Taiwan \\ ${ }^{\mathrm{d}}$ Department of Environmental Engineering, Lan-Yang Institute of Technology, I-Lan 261, Taiwan
}

Received 18 July 2001; accepted 3 March 2002

\begin{abstract}
Waste newspaper, one of the principal waste papers in Taiwan, was pyrolyzed with a thermogravimetric analysis (TGA) reaction system. The pyrolysis experiments were carried out in nitrogen environment at a constant heating rate of $5 \mathrm{~K} \mathrm{~min}^{-1}$. The pyrolysis products and the residues were collected and analyzed by gas chromatography and elemental analyzer, respectively. The major products investigated included non-hydrocarbons $\left(\mathrm{H}_{2}, \mathrm{CO}, \mathrm{CO}_{2}\right.$, and $\left.\mathrm{H}_{2} \mathrm{O}\right)$ and hydrocarbons $\left(\mathrm{C}_{1-3}, \mathrm{C}_{4}, \mathrm{C}_{5}, \mathrm{C}_{6}\right.$, 1-ring, $\mathrm{C}_{10-12}$, levoglucosan, $\mathrm{C}_{13-15}$, and $\left.\mathrm{C}_{16-18}\right)$. The cumulated masses and the instantaneous concentrations of pyrolysis products were obtained under the experimental conditions. The estimation of the mass of tar, yielded at various pyrolysis temperatures, was also made. The results of this study might be useful for the design of pyrolysis process as well as for determining the pyrolysis mechanisms of the newspaper.
\end{abstract}

(C) 2002 Elsevier Science B.V. All rights reserved.

Keywords: Newspaper; Pyrolysis products; Thermogravimetric analysis

\section{Introduction}

The disposal of municipal solid waste (MSW) has become an increasingly intricate and costly problem because of the decrease in the available space for

\footnotetext{
* Corresponding author.
} 
landfills and the growing concern about the living environment. Some studies and reviewed literature indicated that a proper thermal pyrolysis method might be used to resolve the disposal problems and make an energy conversion from MSW [1-6]. Typically, on a dry basis, MSW consisted of paper (28.95\%), cellulosic cloth $(8.11 \%)$, yard waste $(3.10 \%)$, food $(23.18 \%)$, plastic $(19.59 \%)$, leather and rubber $(0.43 \%)$, metals $(7.89 \%)$, glass $(6.98 \%)$, and ceramic, earthen materials and miscellaneous $(1.77 \%)$ in Taiwan [7]. Newsprint was a main component of waste papers of MSW [8]. Since the waste newspaper contained a high calorific value of about $17000 \mathrm{~kJ} \mathrm{~kg}^{-1}$ on a dry basis, its conversion to marketable fuels has become a noble goal from not only an economic, but also from an environmental standpoint.

Newspaper is one of the cellulosic materials. It consists mostly of mechanical pulp and a fraction of chemical pulp. Hemicellulose and cellulose are the principal components of mechanical and chemical pulps, respectively. Studies on the pyrolysis of cellulose and hemicellulose have been performed by many researchers. These studies were concerned mostly about the thermal degradation of pure cellulose or hemicellulose and focused on the analyses of products [9-11], the effects of reaction conditions [12-14], the mechanisms of reactions and the pyrolysis kinetics [15-20]. Some studies have been conducted to investigate the pyrolysis kinetics [21-25] and products [26,27] of waste papers. Cozzani et al. [21] investigated the pyrolysis behavior of different refuse derived fuels (RDFs) under the typical heating rates of conventional pyrolysis process. The main RDF components were paper, wood-like materials, and plastics mainly polyethylene (PE). A kinetic model was developed to describe the thermal degradation of RDFs. Also, a simplified two-reaction model was proposed to illustrate the pyrolysis kinetic behavior of paper mixtures [22] and uncoated [23]/coated [24] printing and writing papers over 450-850 K temperature range. The corresponding activation energies, pre-exponential factors, and reaction orders for four type waste papers (newspaper, uncoated/coated printing and writing paper, and tissue paper) were determined in the experimental conditions. Sorum et al. [25] explored the pyrolysis characteristic and kinetics of MSW. The results indicated that the cellulosic fraction of MSW was modeled by three independent parallel reactions describing the degradation of hemicellulose, cellulose, and lignin. The reactivity of cellulosic matter was increased in a mixture with polyvinyl chloride (PVC). Galletti et al. [26] investigated the pyrolysis products of paperboards from waste paper and wheat straw pulps. The results indicated that the pyrolytic compounds from straw pulp and from waste paper pulp were essentially the same. Li et al. [27] investigated the pyrolysis products of MSW components (paper, paperboards, PVC, PE, rubber, vegetal materials, wood, and orange husk) by a laboratory-scale rotary kiln. The effects of heating methods, moisture contents, and size of waste on the pyrolysis gas and compositions were evaluated. The results of previous studies provided some knowledge of determining the pyrolysis kinetics and products of cellulose, hemicellulose, and cellulosic materials but they have not provided the related data about the pyrolysis products distribution of newspaper of MSW.

Thus the aim of the present work is to deal with newspaper of MSW with a view of providing the major products distribution as well as the variations of cumulated 
masses of pyrolysis products, residues, and estimated tar with pyrolysis temperature. The pyrolysis of newspaper was studied by the thermogravimetric analysis (TGA) reaction system at a constant heating rate of $5 \mathrm{~K} \mathrm{~min}^{-1}$. The experiments were carried out over a wide temperature range $(450-950 \mathrm{~K})$ and in the absence of gasifying agents. Nitrogen was used as the carrier gas. The pyrolysis products and the residues were collected and analyzed by gas chromatography (GC) and elemental analyzer. All these results are useful for determining the pyrolysis mechanisms and for applying the pyrolytic treatment of the waste newspaper of MSW.

\section{Experimental}

\subsection{Materials}

Commercial-grade newspaper was used in this study. It was supplied by the Chung Shing Paper Co., Ltd. of Taiwan, with the properties as described previously [22]. The nitrogen was purchased from the Ching Feng Harng Co., Ltd. of Taiwan, and had a purity of $99.9999 \%$.

\subsection{Pyrolysis apparatus and procedures}

The experiments for the pyrolysis of newspaper were carried out with a TGA reaction system as shown in Fig. 1. The electrical balance (Cahn-1000, USA; with $0.001 \mathrm{mg}$ readability) was used. A sample of known mass $(20 \pm 0.5 \mathrm{mg})$ was placed on a small quartz disk (with $2 \mathrm{~cm}$ diameter and $1 \mathrm{~mm}$ thickness). The disk was hung on the suspension wire (made of platinum with $0.18 \mathrm{~mm}$ diameter) of the

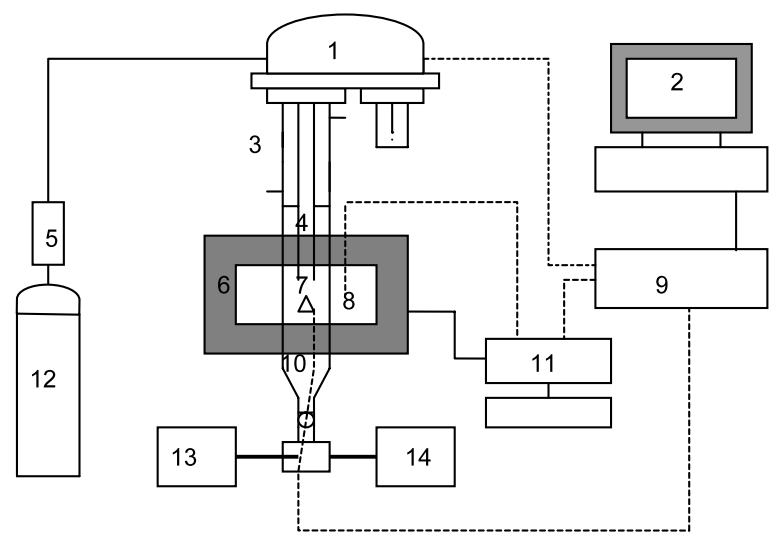

Fig. 1. Schematic diagram of apparatus for pyrolysis of newspaper. 1: Electrobalance, 2: Computer for data-processing, 3: Condenser, 4: Wire, 5: Flow meter with needle valve, 6: Furnace, 7: Sample pan, 8, 10: K-type thermocouples, 9: Mass and temperature data acquisition system, 11: Temperature controller, 12: Nitrogen, 13: Humidity and temperature indicator, 14: Sampling bag. 
balance and enclosed in a quartz shell and tube reactor. The outer shell was $27 \mathrm{~cm}$ long with a $3.8-\mathrm{cm}$ inside diameter. The inner tube was $22 \mathrm{~cm}$ long with a $1.2-\mathrm{cm}$ inside diameter. The nitrogen at a high flow rate was first introduced into the rear channel of the balance protector for $1 \mathrm{~h}$ to purge out the residual oxygen. It was then adjusted to the desired flow rate $\left(50 \mathrm{~cm}^{3} \mathrm{~min}^{-1}\right.$ at $300 \mathrm{~K}$ and $1 \mathrm{~atm}$, controlled by a Cole-Parmer N062-01ST rotameter) and switched over to the inner tube of the reactor. After about $0.5 \mathrm{~h}$, the reactor was placed in the furnace (HAS 100/250G with $1280 \mathrm{~W})$, which had been pre-set to a specified heating rate $\left(5 \mathrm{~K} \mathrm{~min}^{-1}\right)$. When the control units (Eurotherm 815S with RS232 interface) were all ready, the experimental run of pyrolysis was begun. At the same time, the variations of the sample mass and of the reaction temperature (probed with a K-type thermocouple) during the entire pyrolysis process were recorded at time intervals of $10 \mathrm{~s}$ by the data-processing unit (IBM PC-AT 586 with RS232 interface). The pyrolysis process was operated under atmospheric pressure. The pyrolysis products and the residues were collected at some specified temperature ranges (or temperatures). The pyrolysis products and the residues were analyzed by GC and by elemental analyzer, respectively.

\subsection{Sampling and analysis of volatiles}

The volatiles (gas phase at the pyrolysis temperatures) were collected at the exit of reactor. The discrete sampling and the cumulated sampling methods were employed to collect the volatiles. For the discrete sampling method, the volatiles were collected in the $1 \mathrm{dm}^{3}$ sampling bags for the temperatures of $475-950 \mathrm{~K}$ in 25 $\mathrm{K}$ increments. The temperature of the volatiles before the GC/FID, MS analyses was kept at $333 \mathrm{~K}$ by an oven. The instantaneous concentrations of volatiles at the temperatures of $488-938 \mathrm{~K}$ in $25 \mathrm{~K}$ increments are corresponding to above temperature ranges, respectively. For the cumulated sampling method, the cumulated volatiles corresponding to the principal reaction temperature range (475-950 $\mathrm{K})$ were collected in a $5 \mathrm{dm}^{3}$ sampling bag.

The Varian chromatography equipped with an INCOS 50 B mass spectrometer detector and a Supelco SPB-1 capillary column was used to identify some major components in the pyrolysis products. A China Chromatography 8900 GC equipped with a flame ionization detector (FID) and a thermal conductivity detector (TCD) was used to analyze the hydrocarbons (HCs) and non-hydrocarbons (non-HCs), respectively. The purity of gas standards was $99.9999 \%$ for $\mathrm{N}_{2}$, $99.9 \%$ for $\mathrm{CO}_{2}, 99.7 \%$ for $\mathrm{CO}$, and $99 \%$ for $\mathrm{H}_{2}$, and $100 \mathrm{ppm}$ for $\mathrm{C}_{1}-\mathrm{C}_{6}$ in $\mathrm{N}_{2}$, respectively. The concentration of $\mathrm{H}_{2} \mathrm{O}$ in the pyrolysis products stream was detected by the psychrometer (HT-3003, Lutron).

\subsection{Sampling and analysis of residues}

The mass of used sample for the experiments of sampling and analysis of residues was $20 \pm 0.5 \mathrm{mg}$. The pyrolytic reactions were stopped at some specific temperatures e.g. 583, 700, 723, and $938 \mathrm{~K}$, so as to collect the residues. The residues corresponding to these pyrolysis temperatures were then analyzed. 
The elemental analyses for the initial sample and the residues were made on a Perkin-Elmer, Norwalk, CT 2400 (with $0.3 \%$ accuracy) elemental analyzer. The heavy metals in the initial sample were analyzed by the inductively coupled plasma-atomic emission spectrometer (ICP-AES; Germany Kontron S-35). The mass of initial sample used for the analysis of heavy metals was $100 \mathrm{mg}$. The sample mixed with strong acids $\left(3 \mathrm{~cm}^{3} \mathrm{HNO}_{3}, 1 \mathrm{~cm}^{3} \mathrm{HClO}_{4}\right.$, and $\left.1 \mathrm{~cm}^{3} \mathrm{HF}\right)$ was digested at $443 \mathrm{~K}$ for $4 \mathrm{~h}$. It was then diluted to $100 \mathrm{~cm}^{3}$ with pure $\mathrm{H}_{2} \mathrm{O}$ and analyzed by the ICP-AES.

\section{Results and discussion}

\subsection{Solid residues}

Solid residues, at some specific extents of mass change, were collected and analyzed by the elemental analyzer for determining the major elements and providing the evidence to support the pyrolysis mechanisms of two-reaction model [22]. The results of elemental analyses are summarized in Table 1. These results indicated that carbon $(\mathrm{C})$, hydrogen $(\mathrm{H})$, and oxygen $(\mathrm{O})$ were the major constituents of solid residues. The $\mathrm{C} / \mathrm{H}$ mass ratios of solid residues were about 6.96 , $13.11,16.57,18.66$, and 12.64 at pyrolysis temperatures of $300,583,700,723$, and $938 \mathrm{~K}$, respectively. The $\mathrm{C} / \mathrm{O}$ mass ratios of solid residues were about $0.94,1.13$, 1.67 , and 2.67 at pyrolysis temperatures of $300,583,700$, and $723 \mathrm{~K}$, respectively. This indicated that the devolatilization reaction (first stage mass change) was significant from 500 to $640 \mathrm{~K}$ [22]. The products of this reaction stage were intermediates and low molecular mass volatiles (e.g. $\mathrm{H}_{2}, \mathrm{HCs}, \mathrm{H}_{2} \mathrm{O}$, etc.). This was also supported by the product distribution. The sulfur and chlorine in the initial sample and residues were not detected in the elemental analysis (Table 1). This indicated that the potential for treating the pollutants $\mathrm{SOx}$ and $\mathrm{HCl}$ from the pyrolysis of waste newspaper might be negligible. In the second stage mass change $(640-950 \mathrm{~K})$, the intermediates further reacted to form volatiles and solid residues. The mass percent of $\mathrm{C}$ based on the initial sample decreased from $34.47 \%$ (at 583 $\mathrm{K}$ ) to $0.82 \%$ (at $938 \mathrm{~K}$ ). This may be ascribed to the pyrolysis reactions and the gasification of $\mathrm{C}$ to $\mathrm{CO}$ and $\mathrm{CO}_{2}$ at the second stage mass change. This was also observed in the products distributions. From the experimental results, the final residual mass was about $9.45 \%$ of the initial sample. The moisture, ash, and combustible in the proximate analysis of the initial sample were about $1.77,8.70$, and $89.53 \%$, respectively. Based on the dry basis, the percentages of ash and combustible were calculated to be 8.85 and $91.15 \%$, respectively. Since the ash content was analyzed at $1073 \mathrm{~K}$ and in air environment. It was realized that the final residual mass percent was higher than that of ash in the proximate analysis. The major heavy metals in the sample are listed in Table 2. Since the concentrations of the principal heavy metals $(\mathrm{Cr}, \mathrm{Cd}, \mathrm{Pb})$ in the ash were less than $10 \mathrm{ppmm}$. The potential for treating the heavy metals from the pyrolysis of waste newspaper might be negligible. Si and Al were the major inorganic components in the waste 


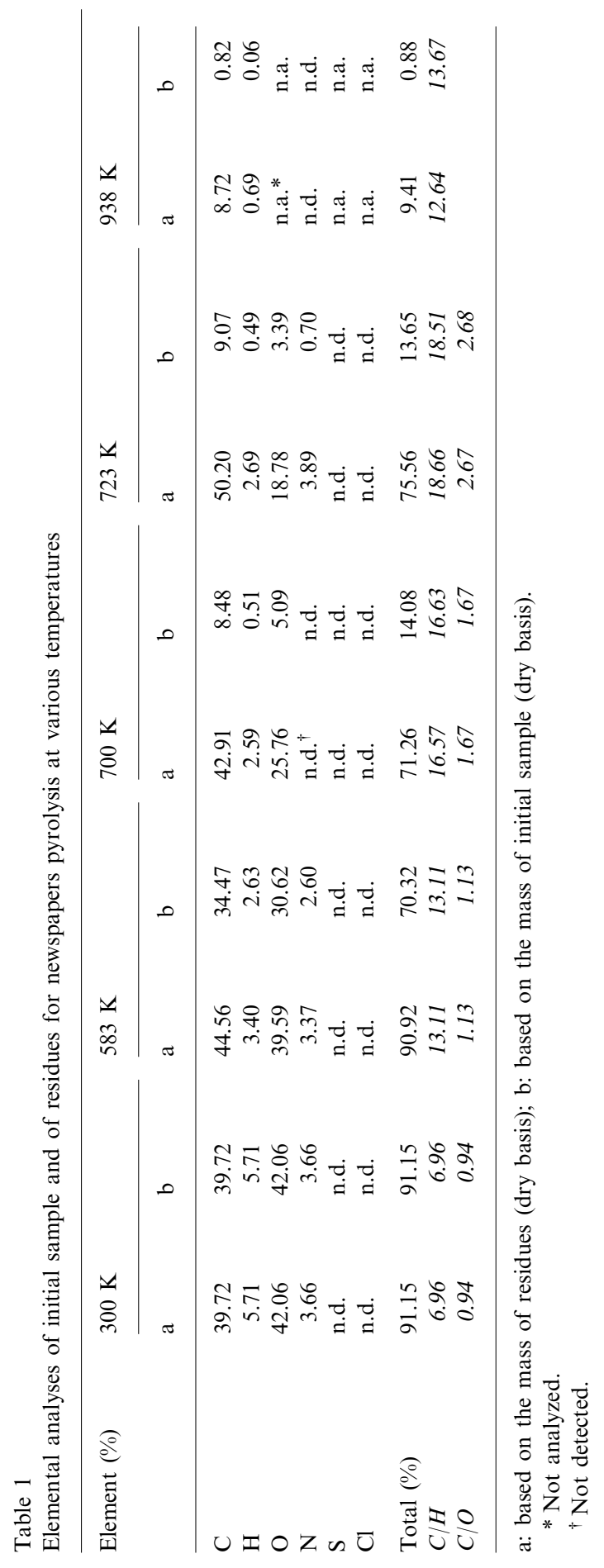


Table 2

Principal metals in initial sample (dry basis)

\begin{tabular}{llllllllllllll}
\hline Species & $\mathrm{Si}$ & $\mathrm{Ca}$ & $\mathrm{Al}$ & $\mathrm{Mg}$ & $\mathrm{Fe}$ & $\mathrm{Cr}$ & $\mathrm{Mn}$ & $\mathrm{Zn}$ & $\mathrm{Cd}$ & $\mathrm{Pb}$ & Total \\
\hline Conc. (ppmm) & 56950 & 934 & 17553 & 342 & 318 & $<10$ & 36 & $<10$ & $<10$ & $<10$ & 76133 \\
\hline
\end{tabular}

newspapers. The recycling of silicon and/or silica from the residues may be also attractive.

\subsection{Volatiles}

Qualitative and quantitative analyses were performed to determine the volatiles (gas phase at the pyrolysis temperatures) of newspaper. Qualitative analysis of hydrocarbons was carried out by GC/MS. The qualitative constituents of hydrocarbons were classified into nine groups according to the retention times. They are methane, ethylene, ethane, propylene, and propane (group 1), butene, butane, and methanol (group 2), ethanol, furan, pentene, and pentane (group 3), hexene, hexane, benzene, butanol, furfural, and isoamyl alcohol (group 4), toluene, $n$-heptane, 1-octene, octane, xylene, styrene, 1-decene, phenol, $n$-nonane, and dodecene (group 5), naphthalene, dodecane, acenaphthylene, and acenaphthene (group 6), levoglucosan (group 7), fluorene, phenanthrene, and anthracene (group 8), and fluouanthene, pyrene, benzo(a)-anthracene, and chrysene (group 9). The results indicated that there were some compounds observed in the retention time ranges of polycyclic aromatic hydrocarbons (PAHs, such as naphthalene, acenaphthylene, acenaphthene, fluorene, phenanthrene, anthracene, fluouanthene, pyrene, benzo(a)anthracene, and chrysene). This suggests that PAHs may be released in the pyrolysis or incomplete combustion process for treating waste newspapers. The similar results were also obtained in previous work $[11,26]$.

Quantitative analysis of volatiles was analyzed by GC/FID (for HCs), GC/TCD (for $\mathrm{H}_{2}, \mathrm{CO}, \mathrm{CO}_{2}$ ), and psychrometer (for $\mathrm{H}_{2} \mathrm{O}$ ). The concentrations of volatiles were based on the calculation using the linear calibration response equations of standards. The equation was generated for each of gas and liquid standards using a minimum of five different concentrations with three replicates at each concentration. All correlation coefficients $\left(r^{2}\right)$ of linear calibration response curves were great than 0.997 . Since the volatiles consisted of lots of hydrocarbon species. The hydrocarbons were not quantified one by one except levoglucosan and $\mathrm{C}_{1}-\mathrm{C}_{5}$ alkanes. The concentration of each group (except levoglucosan and $\mathrm{C}_{1}-\mathrm{C}_{5}$ alkanes) was determined by calculating the area-concentration ratios of the volatiles corresponding retention time range. The analyses masses of instantaneous concentrations of volatiles corresponding to the reaction temperatures are shown in Figs. 2 and 3. The results indicated that the amount of volatiles was negligible for temperatures lower than $488 \mathrm{~K}$. The maximum instantaneous concentrations occurred at about $763 \mathrm{~K}$ for $\mathrm{H}_{2}, 763 \mathrm{~K}$ for $\mathrm{CO}, 788 \mathrm{~K}$ for $\mathrm{CO}_{2}, 663 \mathrm{~K}$ for $\mathrm{H}_{2} \mathrm{O}$, and $913 \mathrm{~K}$ for $\mathrm{HCs}$, respectively. On examining the TGA curves [22], there were two principal reactions 


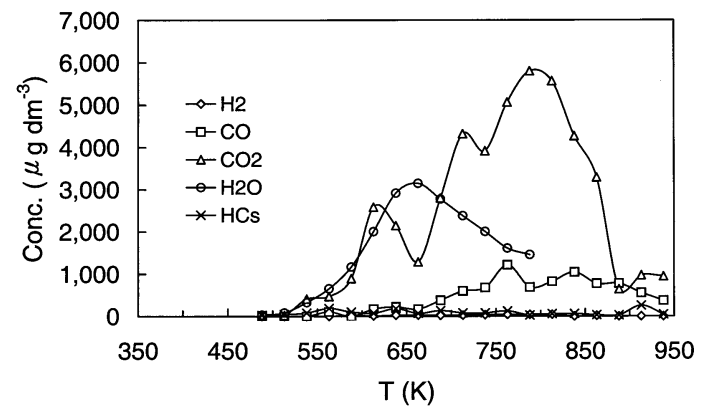

Fig. 2. Variations of instantaneous concentrations of major pyrolysis products with reaction temperature $(T)$.

as distinguished by the two significant and distinct mass changes over the temperature range of $450-950 \mathrm{~K}$. In the preceding section, it was noted that the release of low molecular mass compounds $\left(\mathrm{H}_{2}, \mathrm{HCs}, \mathrm{H}_{2} \mathrm{O}\right.$, etc.) was significant from 500 to $640 \mathrm{~K}$, while that of volatiles $\left(\mathrm{CO}, \mathrm{CO}_{2}, \mathrm{HCs}\right.$, etc. $)$ by gasification reaction or further pyrolysis of intermediates was significant from 640 to $950 \mathrm{~K}$. Thus, it was supported by the analysis of instantaneous concentrations at various reaction temperature ranges.

The analyses of cumulated masses are listed in Table 3 and shown in Fig. 4 and Fig. 5. At $938 \mathrm{~K}$, the masses of major products relative to the initial sample were $0.40 \%$ for $\mathrm{H}_{2}, 10.71 \%$ for $\mathrm{CO}, 56.77 \%$ for $\mathrm{CO}_{2}, 20.57 \%$ for $\mathrm{H}_{2} \mathrm{O}$, and $2.11 \%$ for $\mathrm{HCs}$, respectively. The percentages of major hydrocarbons relative to the total $\mathrm{HCs}$ gases were about $5.21 \%$ for group $1\left(\mathrm{C}_{1-3}\right), 6.64 \%$ for group $3\left(\mathrm{C}_{5}\right), 5.69 \%$ for group $6\left(\mathrm{C}_{10-12}\right), 63.03 \%$ for group 7 (levoglucosan), and $7.11 \%$ for group $8\left(\mathrm{C}_{13-15}\right)$, respectively. Levoglucosan was the major compound of hydrocarbons. The yields of non-hydrocarbons and of hydrocarbons were about 4.22 and $0.53 \%$ at $583 \mathrm{~K}, 32.14$ and $1.19 \%$ at $700 \mathrm{~K}, 63.35$ and $1.51 \%$ at $788 \mathrm{~K}$, and 88.45 and $2.11 \%$ at $938 \mathrm{~K}$, respectively. The results indicated that the non-hydrocarbons were the major pyrolysis products.

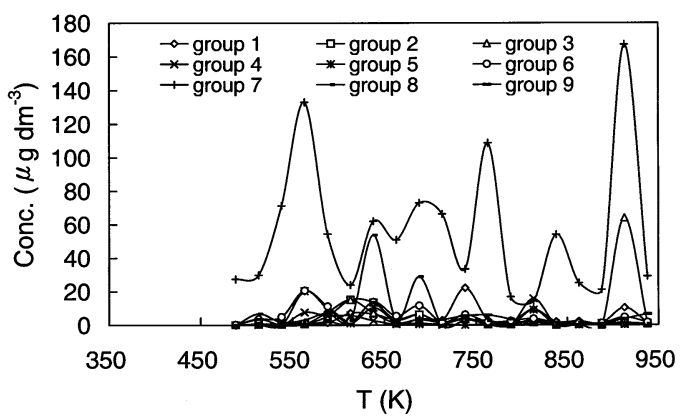

Fig. 3. Variations of instantaneous concentrations of hydrocarbons with reaction temperature $(T)$. 
Table 3

Cumulated mass percents (\%) of various products relative to initial sample (dry basis) at some significant temperatures

\begin{tabular}{lcrrr}
\hline Product & $583 \mathrm{~K}$ & $700 \mathrm{~K}$ & $788 \mathrm{~K}$ & $938 \mathrm{~K}$ \\
\hline $\mathrm{H}_{2}$ & 0.02 & 0.16 & 0.32 & 0.40 \\
$\mathrm{CO}$ & 0.13 & 1.69 & 5.29 & 10.71 \\
$\mathrm{CO}_{2}$ & 2.04 & 15.99 & 37.17 & 56.77 \\
$\mathrm{H}_{2} \mathrm{O}$ & 2.03 & 14.30 & 20.57 & 20.57 \\
Group 1 & 0.00 & 0.04 & 0.07 & 0.11 \\
Group 2 & 0.01 & 0.06 & 0.06 & 0.07 \\
Group 3 & 0.01 & 0.05 & 0.05 & 0.14 \\
Group 4 & 0.01 & 0.03 & 0.03 & 0.05 \\
Group 5 & 0.04 & 0.06 & 0.06 & 0.07 \\
Group 6 & 0.05 & 0.09 & 0.11 & 0.12 \\
Group 7 & 0.38 & 0.70 & 0.94 & 1.33 \\
Group 8 & 0.02 & 0.13 & 0.14 & 0.15 \\
Group 9 & 0.01 & 0.03 & 0.05 & 0.07 \\
Non-HCs & 4.22 & 32.14 & 63.35 & 88.45 \\
HCs & 0.53 & 1.19 & 1.51 & 2.11 \\
Volatiles & $\mathbf{4 . 7 5}$ & $\mathbf{3 3 . 3 3}$ & $\mathbf{6 4 . 8 6}$ & $\mathbf{9 0 . 5 6}$ \\
Residues & $\mathbf{7 5 . 7 7}$ & $\mathbf{1 9 . 7 7}$ & $\mathbf{1 4 . 7 4}$ & $\mathbf{9 . 4 5}$ \\
Volatiles and residues & 80.52 & 53.10 & 79.60 & 100.01 \\
Estimated tar & $\mathbf{1 9 . 4 8}$ & $\mathbf{4 6 . 9 0}$ & $\mathbf{2 0 . 4 0}$ & $\mathbf{0}$ \\
\hline
\end{tabular}

a $\operatorname{Tar}=100 \%-($ volatiles + residues $)$, set to zero if value is negative.

In view of the principal components of newspaper, cellulose is composed of D-glucose units $\left(\mathrm{C}_{6} \mathrm{H}_{10} \mathrm{O}_{5}\right)$ bonded together by ether-type linkages called glycosidic bonds [28]. And hemicellulose contains two to four (and occasionally five or six) simpler sugar residues [28]. D-Xylose, D-glucose, D-mannose, D-galactose, 1-arabinose, D-glucuronic acid, and 4- $O$-methyl-D-glucuronic acid residues constitute the majority of hemicellulose monomers, of which D-xylose $\left(\mathrm{C}_{5} \mathrm{H}_{10} \mathrm{O}\right)$ is the most abundant. The structure of hemicellulose is similar to that of cellulose except that its polymers generally contain 50-200 units, fewer than those of cellulose, and

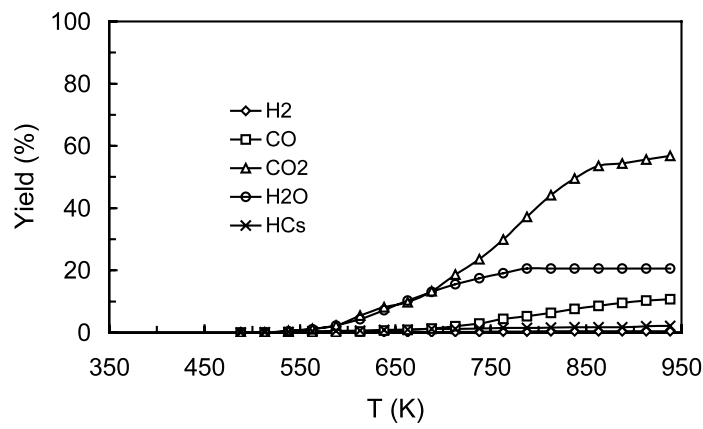

Fig. 4. Yields of major pyrolysis products at various reaction temperatures $(T)$. 


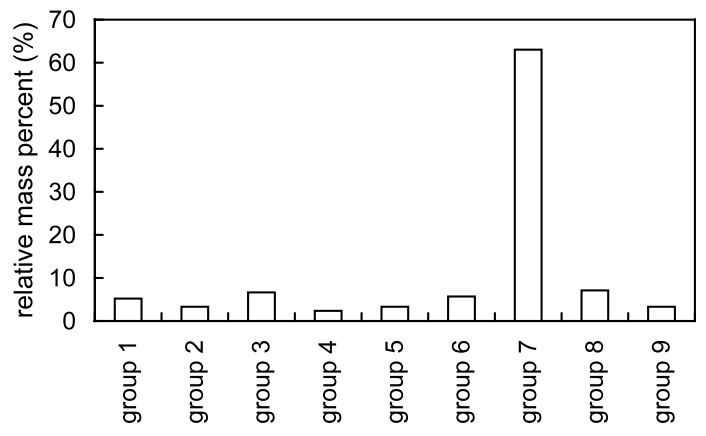

Fig. 5. Percents of groups 1-9 relative to total mass of hydrocarbons.

exhibit a branched rather than a liner structure. Hemicellulose is known to be less thermally stable than cellulose. However, the species of the pyrolysis products are similar to those of cellulose, i.e. $\mathrm{H}_{2} \mathrm{O}, \mathrm{CO}, \mathrm{CO}_{2}$, acetic acid, furfural, levoglucosan, etc. [9]. In this study, the composition of gaseous products $\left(\mathrm{H}_{2}, \mathrm{CO}, \mathrm{CO}_{2}\right.$, low molecular mass compounds) is similar to that of cellulose pyrolysis at atmospheric pressure [9]. From the existing literature [18,19,29], the cellulose decomposed via two competitive reactions: a dehydration reaction to form anhydrocellulose and a depolymerization reaction to levoglucosan at low temperature range $(<573 \mathrm{~K})$. At a higher temperature range, anhydrocellulose later decomposed to char and gas via two competitive reactions to form volatiles/intermediates, and gas/char, respectively. Levoglucosan decomposed to volatiles and char. In this study, the peak concentrations of levoglucosan are at 563, 763, and $913 \mathrm{~K}$ (shown in Fig. 3). According to the pyrolysis mechanisms of cellulose by Mok and Antal [29], the levoglucosan released at $563 \mathrm{~K}$ might be ascribed to the depolymerization (primary reaction) of cellulose. Also, the purge gas flow rate and the pressure in the system might affect the secondary reactions and result in different product distribution [30]. The peak concentrations at 763 and $913 \mathrm{~K}$ might be contributed by the pyrolysis reaction of the other components in newspaper or by the effects of the purge gas flow rate and pressure in the system, which may be explored by a further study.

\subsection{Mass balance}

The mass percents of residues and cumulated pyrolysis products at various reaction temperatures, as shown in Fig. 6, were obtained by the two-reaction model [22] and in this study. According to the proposed model [22], the decrease of the residual mass percent at the first reaction stage (below $640 \mathrm{~K}$ ) was about $72.44 \%$. However, the cumulated mass of the volatiles (gas phase at the pyrolysis temperatures) was only $16.96 \%$ at $638 \mathrm{~K}$. One may reasonably assume that the $V_{1}$ (in two-reaction model) released at this stage consisted of volatiles and liquid tar. The instantaneous and cumulated volatiles quantities were directly obtained from the sampling site. The amount of liquid products (tar) can be estimated from the 
balance of the experimental quantities of solid residues and volatiles. This then gave the distributions of solid residues, liquid products (tar), and volatiles under different temperatures as illustrated in Table 3 and Fig. 6. The maximum rate of tar released occurred at about $638 \mathrm{~K}$. It was further pyrolyzed to light components at a higher temperature range. The similar results were obtained for the rapid pyrolysis of cellulose [31] and milled wood lignin [32]. However, the maximum rate of tar released occurred at about $873 \mathrm{~K}$ in their studies. Since the major components in newspaper are cellulose, hemicellulose with a fraction of impurities. The solid residues at the end of the first stage pyrolysis might consist of inorganics, char (primary and secondary char), and remaining hydrocarbons. According to the pyrolysis mechanisms of cellulosic materials [11] and cellulose [29], the primary char with a strong structural integrity was formed following the decomposition of anhydrocellulose. The secondary char with a loose structure was formed from the depolymerization of levoglucosan. In the second stage reaction $(>640 \mathrm{~K})$, the decrease of the residual mass percent was about $18.11 \%$. The $V_{2}$ (in two-reaction model) were the major products. The product distributions are determined in this study, which are listed in Table 3 and shown in Figs. 2-5. It is noted that the mass percent of the total volatiles from the experimental work was equal to the summation of the masses of $V_{1}$ and $V_{2}$ by the proposed model. The solid char formed in the first stage pyrolysis continued to become more aromatic as temperature increased. According to the results of the pyrolysis of cellulosic materials [11], free radicals were formed in abundance and thermal cracking proceeded above $623-673 \mathrm{~K}$. Elimination of substituents/bridges and dehydrogenation resulted in formatting the polycyclic aromatic clusters. Elimination of oxygen contained in the char occurred simultaneously with the bulk of the hydrocarbon evolution. Elimination of $\mathrm{CO}, \mathrm{CO}_{2}, \mathrm{H}_{2} \mathrm{O}$, and oxygenated aromatics and aliphatics might be part of the process of making aromatic hydrocarbons. PAHs were formed in and evolved from solid char during $673-873 \mathrm{~K}$, even beginning as low as $623 \mathrm{~K}$ for cellulose [11] and $488 \mathrm{~K}$ for newspaper in this work. The results for the pyrolysis of cellulosic materials by Hajaligol [11] were similar to this work and supported by the elemental and pyrolysis products analyses. The results in Fig. 6 indicate that the two-reaction

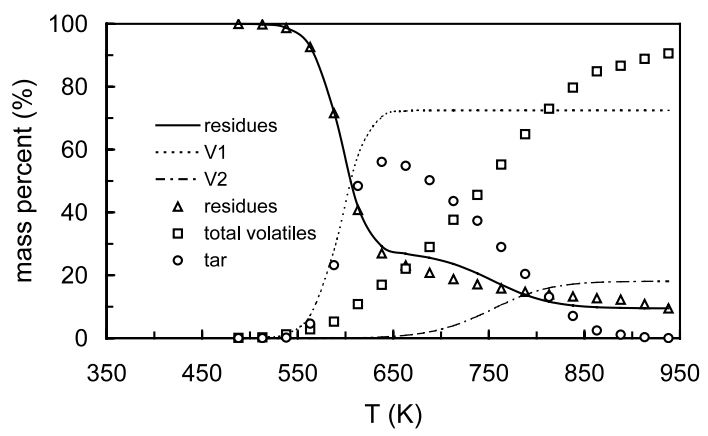

Fig. 6. Mass percents of residues and cumulated products at various reaction temperatures $(T)$. Line: computed; symbol: experimental. 
model gives good agreement with the experimental data for the pyrolysis of waste newspaper.

\section{Conclusions}

Pyrolysis experiments of the newspaper were carried out in a TGA reaction system at a constant heating rate of $5 \mathrm{~K} \mathrm{~min}^{-1}$ and in a nitrogen environment. The pyrolysis products and the residues were collected and analyzed by GC and elemental analyzer, respectively. The major pyrolysis products investigated included non-hydrocarbons $\left(\mathrm{H}_{2}, \mathrm{CO}, \mathrm{CO}_{2}\right.$, and $\left.\mathrm{H}_{2} \mathrm{O}\right)$ and hydrocarbons $\left(\mathrm{C}_{1-3}, \mathrm{C}_{4}, \mathrm{C}_{5}, \mathrm{C}_{6}\right.$, 1-ring, $\mathrm{C}_{10-12}$, levoglucosan, $\mathrm{C}_{13-15}$, and $\mathrm{C}_{16-18}$ ). The cumulated masses and the instantaneous concentrations of pyrolysis products were obtained under the experimental conditions. Since the synthetic gases $\left(\mathrm{CO}, \mathrm{CO}_{2}, \mathrm{H}_{2} \mathrm{O}, \mathrm{HCs}\right)$ contained a high calorific value, their use as marketable fuels greatly supported the importance for resource recycling of the waste newspaper. As the main components in the residues, the utilization of silicon and/or silica may be also attractive.

\section{Acknowledgements}

We express our sincere thanks to the National Science Council of Taiwan for the financial assistance under project NSC 88-2211-E-212-001 and also would like to thank the Chung Shing Paper Co., Ltd. of Taiwan, for providing the newspaper sample.

\section{References}

[1] D.A. Hoffman, R.A. Fitz, Environ. Sci. Technol. 2 (11) (1968) 1023.

[2] A.G. Buekens, J.G. Schoeters, Conserv. Recycling 9 (3) (1986) 253.

[3] A.Z. Aroguz, Z.I. Onsan, Chimica Acta Turcica 15 (1987) 415.

[4] B. Levie, J.P. Diebold, R. West, in: A.V. Bridgwater, J.L. Kuester (Eds.), Research in Thermochemical and Biomass Conversion, Elsevier, London, 1988, p. 312.

[5] N. Mallya, J.E. Helt, Potential for converting MSW to useful fuels through Pyrolysis, Proceedings of Thirteenth National Waste Process Conference, USA, 1988, p. 295.

[6] J. Diebold, R. Evans, J. Scabill, Energy Biomass Wastes 13 (1990) 851.

[7] W.F. Yang, An engineering project for garbage incineration plant of Taipei city: sampling and analyses of garbage at eleventh year, Report of Environmental Protection Bureau of Taipei City, Taiwan (ROC), 1994.

[8] C.H. Wu, Compositions of resource materials in municipal solid wastes, Report of Environmental Protection Administration of Taiwan, Taiwan (ROC), 1999.

[9] O. Beaumont, Wood Fiber Sci. 17 (2) (1985) 228.

[10] I. Simkovic, M. Durindova, V. Mihalov, J. Konigstein, J. Appl. Polym. Sci. 31 (1986) 2433.

[11] M. Hajaligol, B. Waymack, D. Kellogy, Fuel 80 (2001) 1799.

[12] C. Fairbridge, R.A. Ross, S.P. Sood, J. Appl. Polym. Sci. 22 (1978) 497.

[13] F. Shafizadeh, A.G.W. Bradbury, J. Appl. Polym. Sci. 23 (1979) 1431.

[14] M.J. Antal, H.L. Friedman Jr., F.E. Rogers, Combust. Sci. Technol. 21 (1980) 141. 
[15] F.J. Kilzer, A. Broido, Pyrodynamics 2 (1965) 151.

[16] A.G. Bradbury, Y. Sakai, F. Shafizadeh, J. Appl. Polym. Sci. 23 (1979) 3271.

[17] B.K. Gullett, P. Smith, Combust. Flame 67 (1987) 143.

[18] R.K. Agrawal, Can. J. Chem. Eng. 66 (1988) 403.

[19] R.K. Agrawal, Can. J. Chem. Eng. 66 (1988) 413.

[20] M.E. Calahorra, M. Cortazar, J.I. Eguiazabal, G.M. Guzman, J. Appl. Polym. Sci. 37 (1989) 3305.

[21] V. Cozzani, L. Petarca, L. Tognotti, Fuel 74 (6) (1995) 903.

[22] C.H. Wu, C.Y. Chang, J.P. Lin, J.Y. Hwang, J. Chem. Technol. Biotechnol. 68 (1) (1997) 65.

[23] C.Y. Chang, C.H. Wu, J.Y. Hwang, J.P. Lin, W.F. Yang, S.M. Shih, L.W. Chen, F.W. Chang, J. Environ. Eng. 122 (4) (1996) 299.

[24] C.H. Wu, C.Y. Chang, J.P. Lin, J.Y. Hwang, Fuel 76 (12) (1997) 1151.

[25] L. Sorum, M.G. Gronli, J.E. Hustad, Fuel 80 (2001) 1217.

[26] G.C. Galletti, P. Bocchini, M.E. Guadalix, G. Almendros, S. Camarero, A.T. Martinez, Bioresource Technol. 60 (1997) 51.

[27] A.M. Li, X.D. Li, S.Q. Li, Y. Ren, N. Shang, Y. Chi, J.H. Yan, K.F. Cen, Energy 24 (1999) 209.

[28] T.B. Reed, Biomass Gasification Principles and Technology, Noyes Data Corporation, Park Ridge, NJ, 1981.

[29] W.S.L. Mok, M.J. Antal Jr., Thermochimica Acta 68 (1983) 155.

[30] W.S.L. Mok, M.J. Antal Jr., Thermochimica Acta 68 (1983) 165.

[31] M.R. Hajaligol, J.B. Hward, J.P. Longwell, W.A. Peters, Ind. Eng. Chem. Process Des. Dev. 21 (1982) 457.

[32] T.R. Nunn, J.B. Hward, J.P. Longwell, W.A. Peters, Ind. Eng. Chem. Process Des. Dev. 24 (1985) 172. 